\title{
Convergence as a Mechanism of Formation and Development of the Information and Communication Services
}

\author{
Aleksandra N. Nikolayeva ${ }^{1}$, Elena A. Antipova ${ }^{1}$, Larisa G. Vasilyeva ${ }^{1}$, Svetlana V. Petrova ${ }^{1}$, Elena V. Moiseyeva ${ }^{1}$, \\ Sergey V. Kiselev ${ }^{2}$, Elena M. Litvinova ${ }^{3}$ \& Yuliya L. Kamasheva ${ }^{4}$ \\ ${ }^{1}$ Chuvash State Pedagogical University named after I. Y. Yakovlev, Cheboksary, Russia \\ ${ }^{2}$ Kazan National Research Technological University, Kazan, Russia \\ ${ }^{3}$ Russian State Social University, Cheboksary branch, Russia \\ ${ }^{4}$ Institute of Economics, Management and Law, Kazan, Russia \\ Correspondence: Aleksandra N. Nikolayeva, Chuvash State Pedagogical University named after I. Y. Yakovlev, \\ K. Marksa Street 38, Cheboksary, 428032, Russia. E-mail: alfkazan@mail.ru
}

Received: January 19, 2014 Accepted: February 22, 2015 Online Published: March 30, 2015

doi:10.5539/res.v7n5p153 URL: http://dx.doi.org/10.5539/res.v7n5p153

\begin{abstract}
Russia's joining the international information space and increasing competition with foreign communication providers significantly challenges the competitiveness of domestic operators in the market of information-communication services. The authors consider the convergence process in the field of information-communication services in terms of its place and role information and development of the innovative forms of information and communication services, which is characterized as a process of convergence and interpenetration of diverse information and communication technologies that could lead to a qualitatively new technological solutions able to satisfy the demand of today's rapidly changing information environment. The researcher critically analyzes the traditional cycle of the mechanism of creating and implementing information and communication services, justifies the principles and prerequisites for convergence processes in the field of information and communication services, as well as their diffusion into other horizontal and vertical branches of economic activity. This article is intended for the students studying the methods of marketing research in service industries, the teachers of the "Marketing" disciplines as well as marketing managers and managers for communications providers who develop their companies' growth strategies.
\end{abstract}

Keywords: convergence, diffusion, information and communication services, information society, internet, cable TV, competition, demand and supply elasticity, mobile telephone services

\section{Introduction}

\subsection{The Urgency of the Problem}

The democratic processes in Russia's public life and national economy have given momentum to activate the processes of de-monopolization of the telecommunications industry and develop the information and communication services market which has brought to the emergence of competition that subsequently resulted in structuring the market itself. Now it is quite evident in the oligopolistic structure of the information and communication services market, which consistently affects the innovation processes in the industry (Moskalenko, 2006; Gumerov et al., 2015). The innovative projects in the market of information and communication services due to their relatively high capital cost are available only for large companies that can provide the necessary volume of investment flows at all stages of innovation project and particularly at the stage of commercialization (Aksenov, 2004).

The most important prerequisites for activating the innovations diffusion in the information and communication services market is the offer of the largest producers of mobile devices that create a demand; increased competition, relatively rapid market saturation and changing priorities of the these services users (Vasiliev, 2005). As a result the increasing requirements for the quality of information and communication services while maintaining competitive prices determine the urgent need to intensify the innovative development, implement ambitious and long-term innovative projects (Varakin, 2006). 
In this regard, the problem of reasonable and qualitative evaluation of the effectiveness of the commercialization stage of the innovative projects in the information and communication services market is of particular importance both for the companies and consumers of these services, that manifests itself in maintaining a competitive level of availability of these services for population, the shortest payback period of the innovative projects and providing the shareholders with the necessary return on investment (Bershov, 2009).

All this has determined the urgency of the research topic, its theoretical proposition and practical significance.

\section{Methodological Framework}

\subsection{The Research Objectives}

The objective of the study has become a theoretical and methodological rationale for evaluating the effectiveness of convergence as a mechanism of information and communication services formation and development, the rationale for the importance and role of the convergent approach to creating and developing the innovative forms of information and communication services, the analysis and identification of prerequisites and specificity of the innovative products commercialization on the market of information and communication services.

\subsection{Theoretical and Methodological Framework}

The theoretical and methodological basis of the study is built upon the studies of Russian and foreign scientists in the field of innovative development of the information and communication services, the effectiveness of new forms and methods of information support using different types of communication, financial and organizational methods and management mechanisms of the innovative development of communication and information means, special editions and publications in the reviewed journals.

In the course of research the authors applied the dialectical and system analysis, the methods of scientific abstraction and comparison, statistical surveys, economic and mathematical methods in the calculation of averages, the economic indicators groupings, modeling techniques and expert analysis.

\section{Results}

\subsection{The Prerequisites for the Emergence and Functioning of the Convergence Mechanism in the Process of Formation and Development of Innovative Information and Communication Services}

The convergence mechanism and its role in the process of formation and development of innovative information and communication services is assessed by experts as the dominant potential of all innovative development of this sector. It is the convergence as a process of rapprochement and interpenetration of the diverse information and communication technologies can lead to qualitatively new technological solutions that satisfies the demand of today's rapidly changing information environment. So, today in some developed countries the projects of telecommunications and information networks convergence are being implemented. The projects include the combination of Internet services, cable television and telephone services (TPS-Triple-Play Services) which, according to experts, will become one of the key milestones of the nearest decade in terms of information and communication technologies and services (Byron, 2007).

The emergence of the global Internet and computerization of all spheres of social life have generated the need in using packet switching technologies (Bershov, 2009), the convergence of telecommunication and information technologies and thereupon provision of a qualitatively new type of services-information and communication ones. In this case, it is essential that information and communication services can be provided only by means of multi-service networks that have appeared as a result of logic development of switching telecommunication networks and computer networks.

The convergence processes have led to transformation of information and communication services management, which is characterized by transition from the management of certain information resources of the communications enterprise to the management of the services that are based on these resources. Moreover, the technology of providing information and communication services does not exclusively depend on communication technologies, there is a possibility to manage these services from both the user and the service provider (Kuzovkova \& Tymoshenko, 2009). This allows to access the services regardless of the technology used which allows improving the information and communication services management to a new level. In other words, the process of integration, mutual diffusion of information and communication services in the process of convergence within a new service reflects the combination of the compatibility options which the user is provided with by communication operators and providers of information resources. This combination gave rise to the emergence of such innovative services as IP telephony, dial-up Internet, entertainment including interactive TV and games, short messaging services, access to call centers (Demchishin \& Svirin, 2011). 
The most prominent representative of the so-called converged information and communication services is IP-telephony service, which combines the two completely different types of service. Thus, the telephony is an apparent communication service while the Internet is an apparent information service. Initially the voice data was transmitted through the telephone network while the IP-networks transmitted data. The IP-telephony technology has combined these separate networks into one, when in order to transfer the digital voice data from the traditional telephone network into the Internet there were invented special "voice gateways" that allowed bringing a phone conversation into the Internet. The conversation was transmitted over long distances and accepted anywhere in the world in the regular telephone network. Moreover, this converged service has received a huge internal impulse to development that enabled IP-telephony providers to offer a new service- a call from a web site or Surf \& Call (Golubitskaya, 2009). It aims to extend e-commerce (Gavrilov, 2009). The Internet users can directly talk to a sales representative or technical support specialist of the enterprise. For the conversation to take place it is necessary to download a small client software, which can usually be found on the same WEB-page (Anikin, 2004).

It seems natural when the economics considers the process of convergence in the field of information and communication services, on the one hand, as a mechanism to improve the competitiveness of the market participants, on the other hand, as the direct object of competition between the entities of the information and communication services market. These processes are determined by the growth of the information and communication services quality as a reflection of the growing demand for such kind of services from consumers. At the same time the user's needs depend on resource requirements, which then transform into particular services of required quality.

\subsection{A Cycle of Developing and Implementing the New Information and Communication Services Based on the Convergence Mechanism}

The users' rapidly growing needs in information and communication services as an economic regularity with an objective necessity causes formation and development of the convergence mechanism, the result of which is creating the new and modifying the existing information and communication services. The cycle of the formation and implementation mechanism of information and communication services based on the model of Moskalenko (Moskalenko, 2006) is presented in Fig. 1.

The vehicle of this mechanism is its inner contradiction lying in rising costs concurrently with the expanding range of the provided services, as in this mechanism the "returns of the scale" fail. Any process of the quantity growth of the provided information and communication services is invariably accompanied by a relevant increase in production and transmission costs, which results in users' increased satisfaction with the services. Accordingly, any quantity reduction of the information and communication services consistently leads to the reduced costs and reduced customer satisfaction.

Therefore, the solution of this problem can be achieved exclusively by managerial approach dealing with the formation of the marketing products, packaging services, through the automated service directly on-request from the independent building blocks that are created and distributed functionally and geographically (Basharin, Gaydamak, Samuylov, \& Yarkina, 2008).

In other words, the principle of multiple use of packet options of the information and communication services allows to improve customer service efficiency and optimize the resource management.

\subsection{The Basic Principles of the Functional Characteristics of Information and Communication Services Based on the Analysis of the Convergence Mechanism}

The theoretic analysis of a number of studies revealing the specifics of information and communication services formation and development as a result of the convergence of basic information and communication services allows to identify a number of fundamental principles that outline their core characteristics:

- A relatively high level of information and communication service availability for all social groups, economic entities, state and municipal authorities, non-governmental organizations (Varakin, 2006);

- A higher targeting of the information and communication services to ensure its delivery directly to a particular customer; 


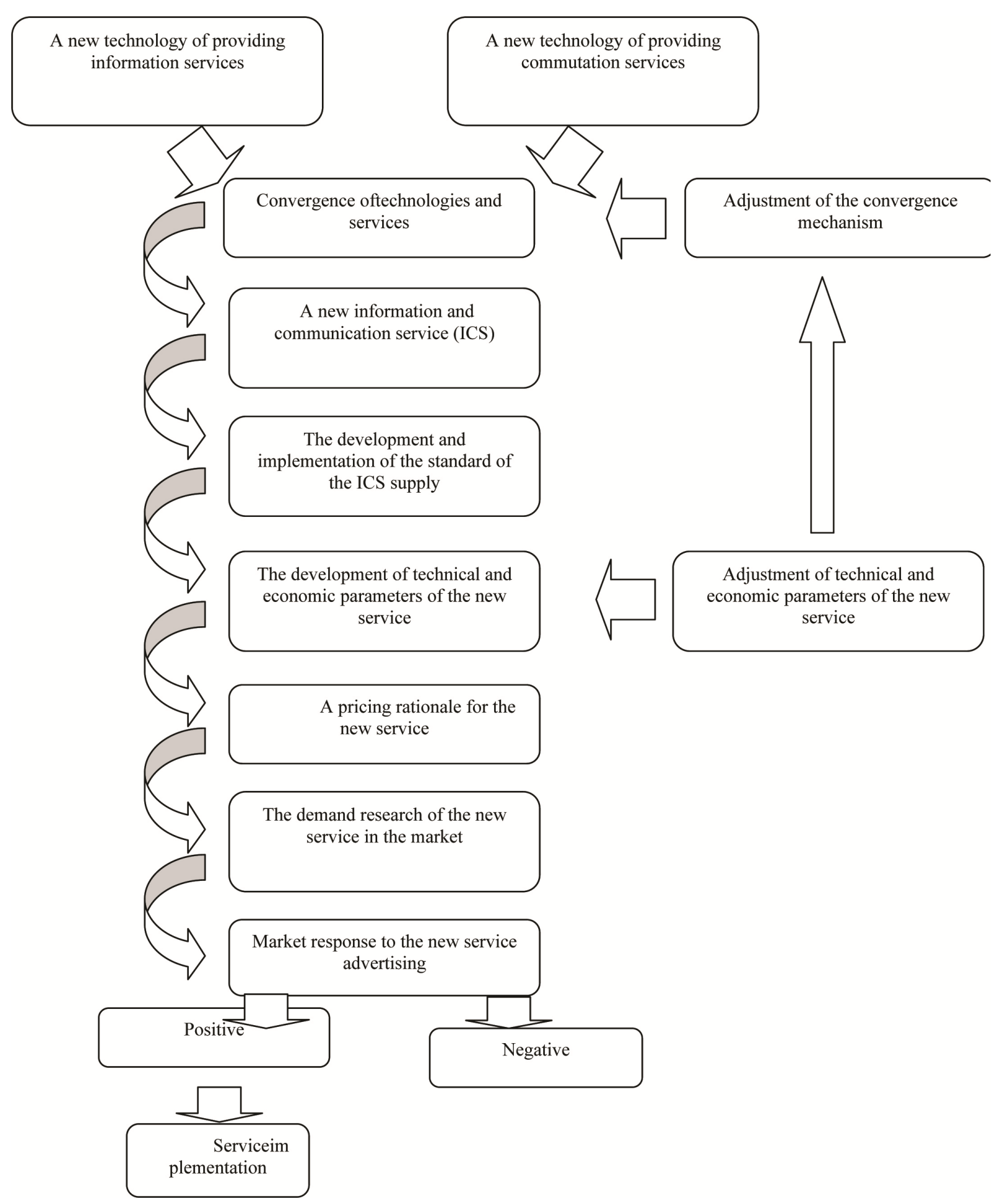

Figure 1. A cycle of developing and implementing the new information and communication services based on the convergence mechanism

- The permanence of information and communication services during their transportation assuming the full identity of the information sent to the recipient user (Vasilev, 2005);

- The legislated responsibility of the operators and providers of information and communication services for information hiding or garbling, breach of confidentiality in the part that does not contravene the law, storage and delivery, targeted delivery without the recipient' consent, in particular, transmitting unnecessary or useless 
information to subscribers;

- A relatively high delivery speed (communication) of information regardless of the distance between its sender and receiver;

- A relatively high level of information and communication services confidentiality, which is guaranteed by the authorities due to the citizens' right of privacy, if the transmitted information does not affect the their life safety;

- The ability to limit the level of information availability, which is regulated by authorities, laws, regulations in mass-media that guarantee the citizens the right to free access to information that does not violate their privacy, as well as by the counter-terrorism law, if the disclosure endangers public security (Kuzovkova, 2009).

The process of implementation of information and communication services is distinguished by the exclusive use of multi-service networks allowing its resources to support basic and additional services, involving transmission over the same communication channel simultaneously of the three kinds of information: voice, video, data. Thus, the information and communication services are the services of integral character generated by a wide range of different terminals and transmitted over a single communication channel with a single equipment (Karnauhova, 2008).

\subsection{The Multilevel Classification of Information and Communication Services}

Some specialists classify all information and communication services conventionally into three categories: information, entertainment and communication (Aksenov, 2004). Nonetheless, this classification seems to quite controversial since such kind of information and communication services as e-books, video on demand, interactive games are immediate information and communication services that combine both information (literature, video, game) and communication services (electronic character, mobility) at the same time. Therefore, the attempt of classification and division of information and communication services into their constituents is incorrect, as it negates this type of service content, which intrinsically is the convergence of information and communication services resulting in a fundamentally new type of service that is qualitatively different from information and communication services individually. For example, voice mail cannot be identified only as a communication service, as its delivery technology only cannot determine its content, that consists of the informative content or information services as well. At the same time, the service access to the Internet services is not legally classified as purely an information service as the most important characteristic of this service content is the degree of accessibility determined by the level of development of communication technologies (Peng, 2003).

Rebrikova (2011) classifies the information and communication services according to three criteria:

- According to "the type of the provided services" which implies a clear distribution of the information and communication services on the independent market segments (IP-telephony, Internet, pay TV)subject to its disunity and absence of integrated market as a whole;

- According to "the model" of provided services where under the classification reflects the way and the number of the requested services provided to the user with a single cable broadband access simultaneously (Single play, Duo play, Triple play, Quadruple play, Multi play) (Kundan \& Misra, 2004);

- According to "subject-consumer" criteria, which allows to make reasonable and miscellaneous portrait of the user to gain a deeper understanding of his needs in this area.

The multi-level classification of information and communication services is shown in Fig. 2.

In other words, information and communication services have their own specific organizational and economic characteristics that imply such basic features as the absence of tangible form and essential impossibility of any change in it except for spatial movement.

3.5 The Evaluation Criteria Including the Level of Supply and Demand Elasticity in the Market Based on the Analysis of Multi-Level Classification of Information and Communication Services

However, other specific characteristics of telecommunications undergo some changes due to a modification of the service nature. For example, if for the telephone service the production and consumption processes are inseparable, then for the information and communication services such as interactive games, home pages, Internet shopping, video services on-demand, unified messaging, contact center services, electronic literature and others this specificity does not apply (Abilov, 2008).

In the process of theoretic analysis of multi-level classification of information and communication services it seems possible to identify the principal evaluation criteria such as the level of demand and supply elasticity for 
these services in the market. So, we have identified a number of specific characteristics of the demand and supply elasticity which are influenced by price, users' income, their age and other parameters. For example, the analysis shows that the price factor is not a constraint for the major groups of consumers of information and communication services, and the demand for information and communication services is not affected by negative market conditions in contrast to similar parameters of demand for other services (Nikiforov, 2011). Thus, the consumers of the information and communication services tend to spend less on entertainment and expensive purchases but they are not ready to decline the Internet and mobile communication services as one of the most important conditions of economic, physical and information security (Gasmi, Laffont, \& Sharkey, 2000).

Thus, the specific parameters of demand and supply elasticity in the process of information and communication services implementation show a weak dependence of the demand for these services from price (tariffs) after the initial market saturation. In other words, the demand for information and communication services is characterized by low elasticity or dependence on prices and consumer income (Kalachanov, 2006).

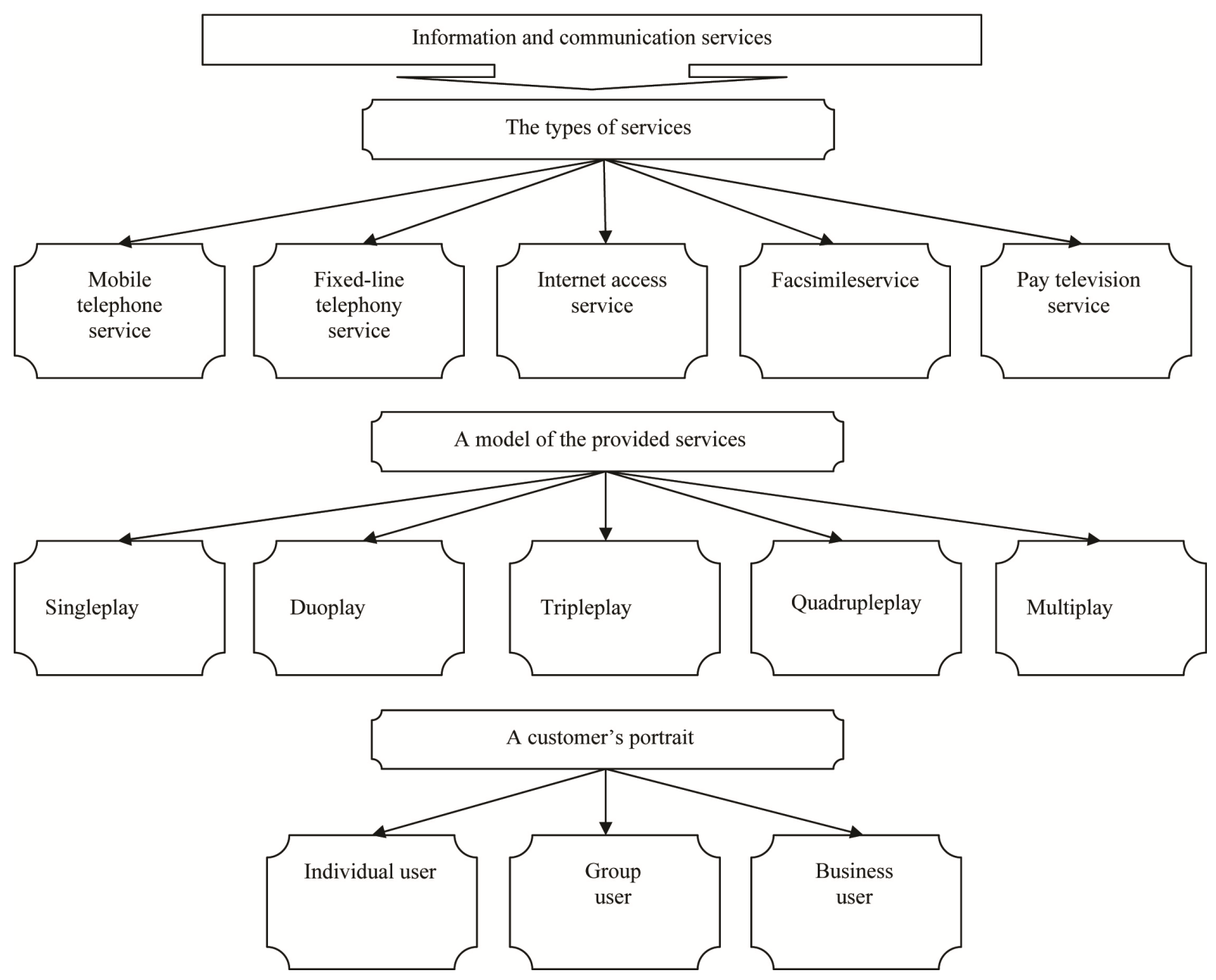

Figure 2. Multi-level classification of information and communication services

In addition, according to experts, the age characteristics of the information and communication service consumers will continue to be dominant in the assessment of the demand elasticity for these services in the nearest five years (Skripkin, 2002). The dominant factor will be the inverse relation of information and communication services consumption to the age of the user. Thus, with theuser's aging the demand for information and communication services will decrease.

\section{Discussions}

The theoretical underpinning of the organizational and economic mechanisms to provide innovative 
development of the service industries, the formation and development of industry-specific, regional, national service marketsis discussed in the works of Abilova (2008), Anikina (2004), Vasilieva (2005), Varakina (2006), Karnaukhova (2008), Kuzovkova (2009), Skripkin (2002) and others.

The study of the economic efficiency of the new forms and methods of supplying information using different types of communication, financial and organizational methods and mechanisms of innovative development of communication and information are devoted the works of foreign scientists Byron (2007), Gasmi and Laffont (2000), Kundan (2004), Myrtle (2008), Peng (2003), Sharkey (2000), as well as national researchers Aliyev \& Basharina (2008), Bersheva (2009), Brusilovskiy (2005), Budanova (2004), Gavrilova (2009), Gaydamak (2008), Golubitskaya (2009), Demchishina (2011), Kalachanova (2006), Nikitina (2005), Samuylova (2008), Smirnova (2005), Yarkina (2008) and others.

However, many questions concerning the assessment of the economic efficiency of the convergence mechanism and commercialization of innovation in the ICT services are still under investigated, as is evidenced by the low rate of introduction of the innovative technologies of the fourth generation.

\section{Conclusion}

Among the important tendencies in the convergence process in the field of information and communication services we should pay attention to their diffusion into other horizontal and vertical branches of economic activity. For example, two-way transmission of information due to the necessity of building a network and participating in the process of transmitting information of several companies acquires a different meaning, as it becomes applicable to the companies in other sectors such as health care, education, trade, tourism, sports, culture and so on.

Further informational support of society and the related convergence of the telecommunication and information structures will lead to the emergence of new demands, and then their satisfaction with new products and services. Converged information and communication services will fully contribute to the development of trade, banking, library, educational, medical and other services. The development of long distance transmitting of audio and video will further expand the range of services in the framework of information and communication technologies which naturally will lead to the acceleration of society informatization.

Therefore, the process of information and communication services diffusion will contribute to the formation and development of a new level of information culture that allows for a targeted work with information using new telecommunication and information technologies.

\section{Recommendations}

The achieved results allow to assess the role and place of convergence as a mechanism of the information and communication services formation and development, to append the tools for assessing the effectiveness of the innovations commercialization in the market of information and communication services, and develop the provisions of the information theory as well.

The results of the research can be used as a basis for further scientific development of the problems concerning information and communication services, market functioning and development through the convergence mechanism, in the practice of all its subjects as well as of general government.

The results may be useful for the students studying the methods of marketing research in service industries, as well as for marketing experts for telecom operators who develop strategies of their companies within management decisions and investment policy for providing information and communication services of the fourth generation.

\section{References}

Abilov, A. V. (2008). The patterns of the development of the regional information and communication complex. Moscow: Goryachayaliniya-Telecom.

Aksenova, E. E. (2004). The methods of assessment and forecast for innovation in the telecommunications infrastructure (Ph.D. thesis). St. Petersburg, Russia.

Anikin, O. B. (2004). The prospects for the development of the global telecommunication services market. Moscow: Progress.

Basharin, G. P., Gaydamak, Y. V., Samuylov, K. E., \& Yarkina, N. V. (2008). The models for the service quality analysis in telecommunication networks of next generation. Moscow: The Peoples' Friendship University of Russia. 
Bershev, S. M., \& Aliyev, N. M. (2009). Packaging of the telecommunication services-From a marketing strategy to implementation. Moscow: IRIAS.

Demchishin, V. I., \& Svirin, A. V. (2011). The estimation of the total current supply in the market of commercial data center (CDC) in the Moscow region. Mir svyazi, 11, 78-83.

Dennis, B. (2007). An Assessment of the TeleManagement Forum's eTOM Model (p. 7). IDC Research.

Gasmi, F., Laffont, J. J., \& Sharkey, W. (2000). Competition, Universal Service and Telecommunications Policy in Developing Countries. Information Economics and Policy, 3, 221-248. http://dx.doi.org/10.1016/S0167-6245(00)00016-0

Gavrilov, L. P. (2009). The fundamentals of e-commerce and business. Moscow:

Golubitskaya, E. A., \& Nikiforov, V. C. (2009). The evolution of the universal service mechanisms in telecommunications: international experience. Rossiskiyvneshneekonomicheskiy Vestnik, 2, 135-140.

Gumerov, A. V., Pavlova, A. V., Kharisova, G. M., Abdullina, S. N., Matveeva, E. S., Vyukov, M. G., \& Khairullina, E. R. (2015). The Role of the Quality Production Process of the Business Entitles in Volatile Environment. Review of European Studies, 7(1), 200-206.

Kalachanov, V. D. (2006). The economical efficiency of information technologies implementation. Moscow: MAI.

Karnaukhova, V. K. (2008). Services activity. Rostov-on-Don.

Kundan, M. (2004). OSS for Telecom Networks: An Introduction to Network Management (p. 402). Springer.

Kuzovkova, T. A., \& Timoshenko, L. S. (2009). The analysis and forecasting for info communication development. Moscow: Goryachayaliniya-Telecom.

Moskalenko, M. U. (2006). The formation and development of information and communication services market (Ph.D. thesis). St. Petersburg, Russia.

Nikiforov, N. A. (2011). The main prerequisites for the formation of public e-services in the Republic of Tatarstan. Bulletin of the Kazan Technological University, 5, 214-223.

Peng, S. (2003). Universal Telecommunications Service in China: Trade Liberalization, Subsidy, and Technology in the Making of Information Equality in the Broadband Era. Asian-Pacific Law \& Policy Journal, 4, 21-49.

Rebrikova, N. V. (2011).The features of marketing of telecommunication services. Bulletin of the Cherepovets State University, 2, 67-72.

Skripkin, K. G. (2002). The economical efficiency of the information systems. Moscow: DMK Press.

Varakin, L. E. (2006). The information-economic law, The Relationship between the info communication infrastructure and economy. Moscow: Mezhdunarodnayaakademiyasvyazi.

Vasilyev, V. V., \& Kuzovkova, T. A. (2005). Information and communication technologies and the information economy. Moscow: Paleotip.

\section{Copyrights}

Copyright for this article is retained by the author(s), with first publication rights granted to the journal. This is an open-access article distributed under the terms and conditions of the Creative Commons Attribution license (http://creativecommons.org/licenses/by/3.0/). 